\title{
THE CONDUPLICATE CARPEL OF CANANGA ODORATA
}

\section{K. Periasamy and B. G. L. Swamy}

Recent investigations by Prof. I. W. Bailey and his colleagues on the representatives of the ranalean families have brought to light several features of great morphological value. Among the more important of these is the concept of the "conduplicate carpel," first put forward by Bailey and Smith (1942), Bailey and Nast (1943), and further elaborated by Bailey and Swamy (1951).

The concept of the conduplicate carpel was primarily the outcome of an effort to understand and interpret the remarkable megasporophyll of the Degeneriaceae, a new family recently added to the Ranales (Bailey and Smith, 1942). According to Bailey and Smith, "The carpel of Degeneria, preceding and during anthesis, resembles an adaxially folded 3-veined sporophyll. . . . Furthermore, the margins of the carpel are not infolded or coherent during ontogeny, but tend to flare apart externally. The placentation is clearly laminar and adaxial." This remarkable nature of the carpel of Degeneria instigated further investigations, and Bailey and Nast (1943) found that not only carpels of a fundamentally similar type occur in the representatives of the Winteraceae, but that this family as a whole exhibits also various trends of phylogenetic modifications of such primitive ranalean megasporophylls. As a result of their investigations on the Degeneriaceae and Winteraceae, Bailey and Nast (1943) concluded that the carpels of these families "do not conform with the classical interpretation of the angiosperm carpel as an involute megasporophyll bearing marginally attached ovules." Following this, Bailey and Swamy (1951) have given a clear and coherent picture of the course of carpel evolution in the Ranales. They have shown that, proceeding from the least modified form of surviving carpel exhibited by Drimys piperita, the various other morphological forms may be derived as logical consequences of certain simple trends of modification.

Although the evidences presented in the contributions cited above are sufficient to warrant a modification of the "classical" view of the carpel which comprehends the megasporophyll of angiosperms as an involute structure with marginal placentation, it is desirable to present further evidence which would strengthen the "conduplicate" view.

The primodia of the carpels of the annonaceous Cananga odorata (Lam.) Hook. f. \& Thoms. arise as peg-like projections from the central region of the somewhat flat thalamus. In a transection, each primordium appears as a solid structure. The adaxial part consists of richly cytoplasmic, meristematic cells, but there is a gradually increasing vacuolation in the cells as one proceeds towards the abaxial face (FIG. 1). As development proceeds, the primordium assumes a roughly triangular outline in transection, with a flattened adaxial side and a more or less conical abaxial side. The 
densely protoplasmic meristematic cells become isolated in two masses along the adaxial side. At the same time, a majority of cells in the abaxial part become highly vacuolate and parenchymatous (FIG. 2). During slightly later stages of differentiation, the marked activity of the two masses of marginal meristems (essentially by periclinal divisions) along the adaxial side brings about the formation of a median longitudinal furrow. In a transection, the furrow appears as a notch, and the two free arms consist of active meristematic cells. The procambium of the median vascular strand of the carpel is also noticeable at this time (FIG. 3). The marginal meristems continue their activity for a time, and as a result, the free arms become longer and the furrow deeper (FIG. 4). Soon, however, there is a cessation of the activity of the meristems and this is indicated by the onset of vacuolation in the hypodermal cell layers of the free arms (FIGS. $4,5)$.

The early ontogenetic stages of the carpel of Cananga odorata just described, show striking resemblances to the development of a simple leaf as described by Foster (1936). According to Foster a leaf primordium, soon after its appearance at the growing point, is "pad-like or peg-shaped." Then, "following the early specialisation of the petiolar midrib region in most simple leaves, the lamina begins to differentiate from its upper portion as two thin marginal ridges of meristems." A comparison of FIG. 3 of Foster (1936) with Fig. 3. of our paper makes it evident that the marginal meristems in both structures are not only homologous but also analogous with each other. Continuing, Foster says that, "marginal growth ceases when the main lobes of the lamina have been formed."

If homology and analogy, which would lead towards a clarification of morphological and phylogenetical ambiguities, may be elucidated from a study of ontogenies, we have here a remarkable exhibition of these principles in the ontogeny of the leaf of angiosperms and that of the carpel of Cananga odorata, so that we can clearly comprehend the fundamentally similar nature of the two structures without the interpolation of any speculative hypothesis. The analogy of the early maturation of the marginal meristem shows that in the carpel of Cananga odorata, laminal differentiation attains normal completion before the inception of the placental ridges, and at the same time negates the possibility of any assumption of "involute margins." The transection of the carpel of Cananga odorata presented in Fig. 4 is a true homologue of a nearly mature, adaxially conduplicate foliar appendage, the entire inner surface of the cleft corresponding to the adaxial surface of the foliar lamina.

The placental ridges make their appearance soon after or simultaneously with the cessation of the activity of the marginal meristem. The ridges, which develop from the adaxial laminar surface of the carpel by the activity of the two undifferentiated groups of meristematic cells are, in the beginning, situated more towards the centre of each half-lamina and are far removed from the true margins (FIG. 5). This is exactly similar to the condition encountered in Degeneria (Swamy 1949), and is probably true of other primitive, unsealed ranalean megasporophylls. Thus, the 

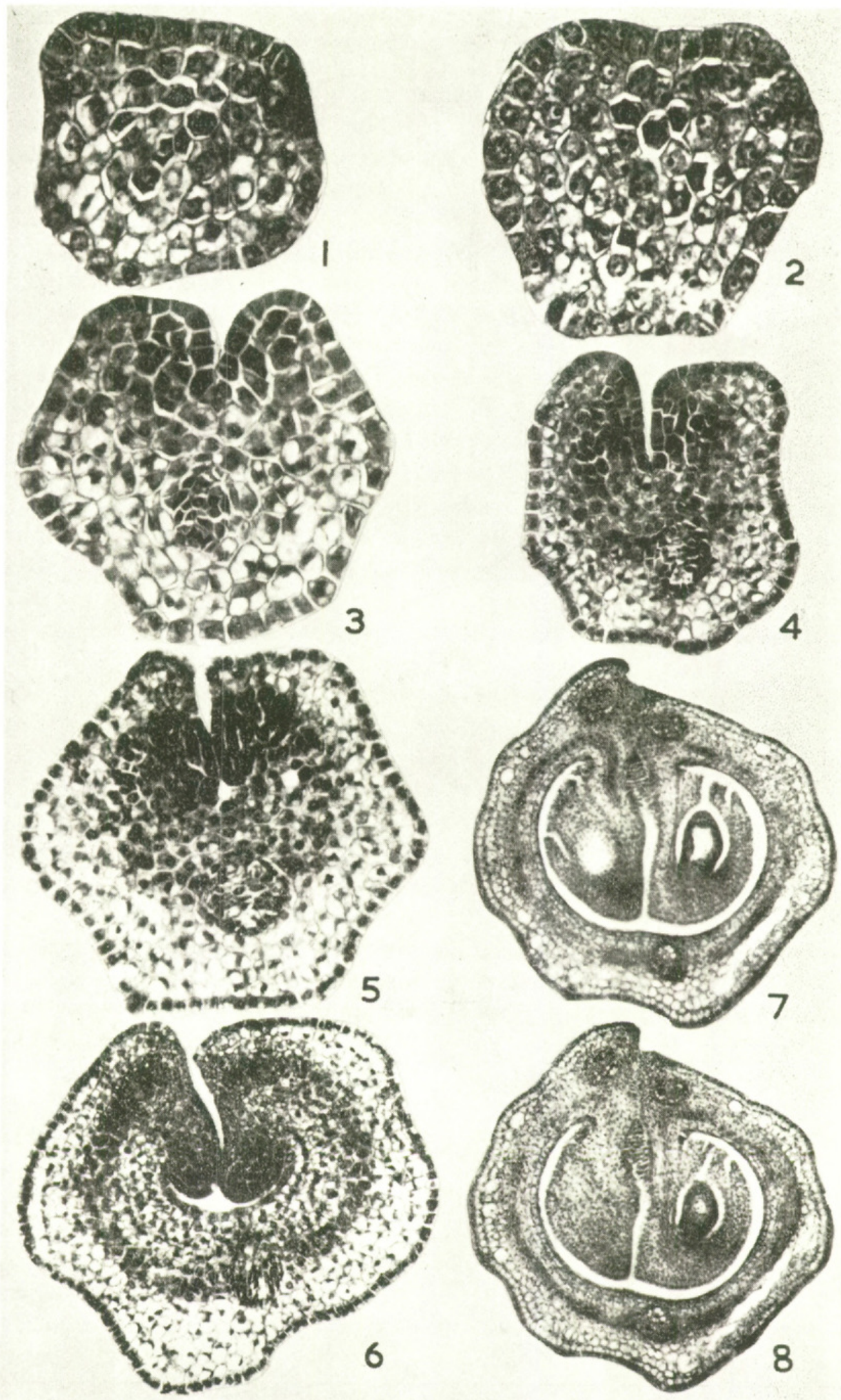

Figs. 1-6. Transections of the carpel of Cananga odorata (Lam.) Hook. f. \& Thoms. during successive stages of ontogeny. For explanations see text. $1 \times 547$; $2 \times 540 ; 3 \times 453 ; 4 \times 240 ; 5 \times 270 ; 6 \times 204$.

Figs. $7 \& 8$. Successive transections of a mature carpel at the time of anthesis, showing the procambial vascular supply to the ovules "given out" from the dorsal trace. $\times 90$. 
location, as well as the manner of initiation and differentiation of the placental ridges do not suggest a "marginal" placentation, or an "involution" of the true carpellary margins. On the other hand, these ontogenetic successions clearly indicate that the placentation is laminar, and the actual margins are not involved in placentation. While in Degeneria, Drimys, and other relatively primitive carpels the sterile marginal portion of the lamina beyond the place of origin of the placental ridges attains an extensive development in the form of externally flaring stigmatic surfaces, in Cananga odorata, there has been a phylogenetic reduction in the activity of the marginal meristem, and consequently of the flaring stigmatic part.

As the placental ridges continue development, the carpel wall undergoes a corresponding abaxial bulging to inclose the cavity of the carpel (FIG. 6). The abaxially directed placental ridges almost fill the cavity of the carpel. The procambium of the ventral vascular strands differentiate within the lamina, at points far removed from the true margins (FIG. 6). As a result of continued abaxial bulging of the carpel wall with a corresponding widening of the cavity of the carpel, the ventral surfaces of the megasporophyll are brought nearer to each other almost to the point of concrescence (Figs. 6, 7, 9). The ovules differentiate from the rim of the placental ridges.

The developmental changes described above are, however, confined only to the lower, ovule-bearing part of the carpels of Cananga. There is very little modification in the upper, stylar and stigmatic regions, where the conduplicate nature remains more or less "set." In these regions, the epidermal cells along the inner surface of the adaxial furrow develop into papillate hairs. A similar differentiation of epidermal hairs takes place also in the ovary cavity around the base of the funicle and in the region of the approximated ventral surfaces of the carpel wall.

It must be emphasized that the ventral surfaces of the carpel do not undergo ontogenetic fusion even during the post-fertilization stages of development. They remain only tightly approximated (Figs. 7-9). On this account, it is possible to open (at least in the pre- and early postfertilization stages) the carpel along the ventral suture, thereby exposing the ovules on the corresponding halves. As commented by Bailey and Swamy (1951), the erroneous concept of involute margins and of marginal placentation is obviously the result of taking into consideration only the end products of phylogenetic specialization without a study of the series of successively modified ontogenies.

The remarkable nature of vascularization of the ovules in Cananga odorata call for special mention as the situation affords additional evidence in favor of the conduplicate concept. The mature carpel of this plant is supplied with two ventral strands and a single median strand (Figs. 7-9). Even though the median strand is the first to differentiate in ontogeny, it remains unbranched even in the mature carpel except for strands which vascularize the ovules. The ventral strands, which differentiate comparatively late in ontogeny, are on the other hand, provided (at maturity) with several branches, all of which extend towards the median strand 

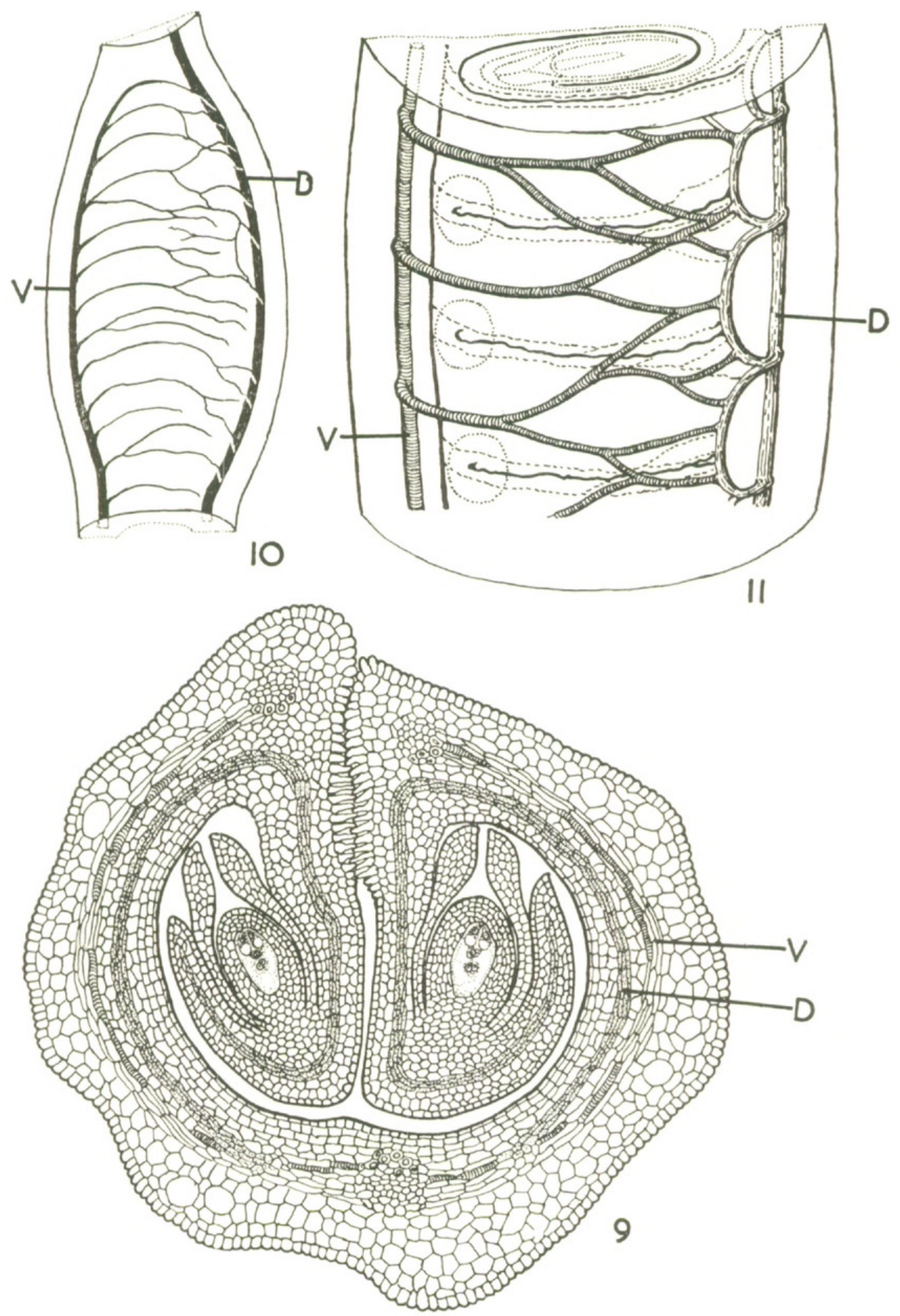

FIG. 9. Semi-diagramatic representation of the transection of a mature carpel. $\times 180$.

FIg. 10. Vasculature of the mature carpel during anthesis as seen in cleared preparations. Style and stigma removed and only one longitudinal half is shown (Semi-diagrammatic).

FIG. 11. Diagrammatic representation of the vasculature of the carpel during early post-fertilization development as seen in cleared preparations. Only a portion of one longitudinal half is shown. The dotted circles indicate the place of insertion of the funicles. $\mathrm{D}=$ Dorsal system of vasculature. $\mathrm{V}=$ Ventral system of vasculature. 
through the corresponding side of the carpel wall. The branches undergo further proliferation and anastomoses, and some of the ultimate endings establish connections with the median strand (FIG. 10). It must be noted, however, that none of these branches belonging to the ventral system is concerned in the vascularization of the ovules.

The vascular supply to the ovules remains procambial in the mature carpel (at the time of anthesis). It is remarkable that they are supplied from branches arising from the median strand, and not from the ventral strands, although the latter are situated nearer to the funicles than is the former (FIgs. 7-9). Thus, as seen in a transection of the mature carpel, the procambial strand, which consists of three to four cell layers in thickness, extends from the funicle directly to the median strand of the carpel through the corresponding side of the wall, and has no connection with the ventral strand of the respective side (Figs. 7-9). During its course through the carpel wall, the ovular strand lies internal to the ventral system of vasculature (FIG. 9). In the vicinity of the median strand, the ovular trace establishes connection with the anastomoses formed by the short branches of the dorsal system (FIG. 9).

The vascular picture of the mature carpel remains without any profound modifications during early post-fertilization development (FIG. 11). Even after the differentiation of tracheary elements, the ovular strands do not establish connection with those of the ventral system (FIG. 11). Any connection between the two is brought about only very late when the vascular skeleton becomes highly complicated by the development of secondary vasculature in the fruit wall.

The vasculature of the carpel of Cananga exhibits an important deviation from other ranalean carpels. In contrast to the condition met with in Canang $a$, it is the dorsal system of vasculature that attains a more extensive development than the ventral system in the mature carpels of Degeneria, Drimys, and other winteraceous representatives (Bailey and Smith, 1942; Bailey and Nast, 1943; Bailey and Swamy, 1951; Swamy, 1949). The singular nature of vascularization of all the ovules from the dorsal system alone is a unique feature of Cananga odorata, and is not known to occur in other ranalean carpels thus far studied. An approach to this condition is, however, seen in Drimys and Degeneria, where the ovules are vascularized in part by ramifications of the ventral veins, and in part by extensions of the dorsal system of veinlets (Swamy, 1949; Bailey and Swamy, 1951)..

While it is true that vascularization of the ovules by the dorsal system is proof of a laminar placentation, it is interesting that such an anatomical pattern should be retained in the carpels of Cananga, which exhibit considerable degree of evolutionary advance in regard to other features. Probably, this situation is yet another remarkable example of the fact that in the modus operandi of organic evolution structural changes do not always proceed at a synchronous rate in all the individual features of an organ concerned. Cumulative evidences from comparative morphological studies are becoming increasingly significant and suggest that while an 
organ may have undergone structural modifications with regard to certain of the characters, it may remain yet unmodified with regard to other features. In fact, it is the recognition, study and understanding of such "varying segments of salient evolutionary sequences" within the assemblage of extant plants themselves that has recently been of great value in enhancing our knowledge of trends in evolutionary history.

\section{SUMMARY}

The early ontogeny of the carpel of Cananga odorata is similar to that of a simple angiospermous foliar appendage. A carpel primordium is at first solid and rounded as seen in transections. During development it assumes a roughly triangular outline with a flattened adaxial side. Marginal meristems which function at both corners of the adaxial face bring about the formation of a furrow on the corresponding side, and the two free arms correspond to the lamina of a leaf. The marginal meristem ceases activity at an early stage. Therefore, the laminar margins do not show any evidence of involution. The placental ridges develop from the adaxial surface of the lamina. Just as the ovule-bearing part, the stylar and stigmatic regions of the carpel also exhibit conduplication.

The mature carpel is vascularized by two ventral strands and a median strand. The ventral strands develop a more extensive system of branches than the dorsal. It is remarkable that the ovules are vascularized by branches of the dorsal strand. The ventral strands are not involved in this phenomenon. Such a situation persists even during the early postfertilization development. The ontogeny of the carpel, the place of origin of the placental ridges, and the unique nature of vasculature of the ovules, are remarkable evidences in favor of the "conduplicate concept" of ranalean carpels. This situation further emphasizes the need for modification of the "Classical View" that looks upon the carpel as possessing involute margins and marginal placentation, and as giving vascular supply to the ovules solely from the marginal (Ventral) vascular strands.

\section{LITERATURE CITED}

Bailey, I. W. And C. G. Nast. 1943. The comparative morphology of the Winteraceae. II. Carpels. Jour. Arnold Arb. 24: 472-481.

and A. C. Smith. 1942. Degeneriaceae, a new family of flowering plants from Fiji. Jour. Arnold Arb. 23: 356-365.

- And B. G. L. Swamy. 1951. The conduplicate carpel of dicotyledons and its initial trends of specialization. Amer. Jour. Bot. 38: 373-379.

Foster, A. S. 1936. Leaf differentiation in angiosperms. Bot. Rev. 2: 349-372.

Swamy, B. G. L. 1949. Further contributions to the morphology of the Degeneriaceae. Jour. Arnold Arb. 30: 10-38.

Department of Botany,

Presidency College,

Madras 5, India. 

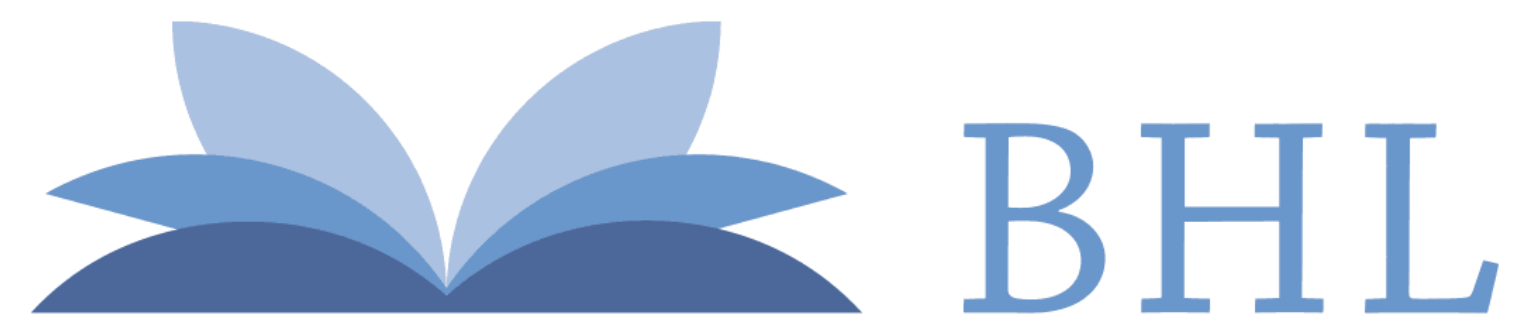

\section{Biodiversity Heritage Library}

Periasamy, K and Swamy, B G L . 1956. "The Conduplicate Carpel of Cananga odorata." Journal of the Arnold Arboretum 37(4), 366-372.

https://doi.org/10.5962/p.186000.

View This Item Online: $\underline{\text { https://www.biodiversitylibrary.org/item/33613 }}$

DOI: https://doi.org/10.5962/p.186000

Permalink: https://www.biodiversitylibrary.org/partpdf/186000

\section{Holding Institution}

Missouri Botanical Garden, Peter H. Raven Library

\section{Sponsored by}

Missouri Botanical Garden

\section{Copyright \& Reuse}

Copyright Status: In copyright. Digitized with the permission of the rights holder.

Rights Holder: Arnold Arboretum of Harvard University

License: http://creativecommons.org/licenses/by-nc-sa/3.0/

Rights: https://biodiversitylibrary.org/permissions

This document was created from content at the Biodiversity Heritage Library, the world's largest open access digital library for biodiversity literature and archives. Visit BHL at https://www.biodiversitylibrary.org. 